\title{
Prevention of biofilm accumulation on a light-activated antimicrobial catheter material
}

\author{
Stefano Perni, ${ }^{* a}$ P. Prokopovich, ${ }^{b}$ Ivan P. Parkin, ${ }^{c}$ Michael Wilson ${ }^{a}$ and Jonathan Pratten ${ }^{a}$ \\ Received 14th June 2010, Accepted 2nd August 2010 \\ DOI: 10.1039/c0jm01891k
}

The colonization of catheters by microorganisms is a serious problem that can lead to the development of resistant biofilm-related infections. Lethal photosensitisation is a possible solution as it is capable of inactivating microorganisms through the generation of reactive oxygen species. Previously we have shown that a Methylene Blue and gold nanoparticle-embedded silicone material has antimicrobial properties against planktonic bacteria when exposed to laser light. In this work the material has been tested for its ability to reduce the formation of Staphylococcus epidermidis biofilms. Biofilm formation was observed over time using a flow cell which was arranged to allow laser irradiation in situ. The duration and frequency of light exposure were changed so that the same amount of energy was delivered during each experiment. Neither short $(5 \mathrm{~min})$ but frequent (every $30 \mathrm{~min}$ ) irradiation nor long $(20 \mathrm{~min}$ ) and infrequent (every $120 \mathrm{~min}$ ) exposure was able to significantly prevent biofilm formation; they resulted in $75 \%$ and $60 \%$, respectively, of the surface covered by the biofilm after 6 hour of colonization compared to $100 \%$ coverage when no laser was used. However, when laser irradiation was performed for $10 \mathrm{~min}$ every $60 \mathrm{~min}$, a reduction in biofilm coverage of greater than $50 \%$ was observed compared to untreated silicone. The properties of the materials post-irradiation were also evaluated; the surface roughness of the material, the asperity density and the asperity height showed a continuous decrease with energy dose. However, the elasticity (Young's module) was not affected by the irradiation. This appears to be a promising novel light-activated material which, as well as displaying antimicrobial activity, has been shown for the first time capable of reducing biofilm formation over time.

\section{Introduction}

Healthcare-associated infections (HCAIs) are defined by the Department of Health as 'any infection by any infectious agent acquired as a consequence of a person's treatment by the National Health Service (NHS)'. The prevention and control of HCAIs, within healthcare institutions both in the UK and worldwide, is a major priority and the revised document from the Department of Health, 'The Health Act 2006: Code of Practice for the Prevention and Control of Healthcare Associated Infections' details standards to achieve these aims. ${ }^{1}$ In the UK, 5000 people die each year as a result of healthcare-associated infections (HCAIs). Many hundreds of thousands of people develop HCAIs which prolong hospital treatment, increase morbidity and mortality and add to treatment costs. The total annual cost of HCAIs is in excess of $£ 1$ billion. The commonest types of HCAIs in the UK are urinary tract infections (UTIs) of which $80 \%$ are associated with the use of catheters. ${ }^{2}$

There is, therefore, a requirement for novel methods to reduce the incidence of HCAIs by targeting the inherently resistant

\footnotetext{
${ }^{a}$ Microbial Diseases, UCL Eastman Dental Institute, University College London, 256 Gray's Inn Road, London, WC1X 8LD, UK. E-mail: s.perni@ucl.ac.uk; Fax: +44 (0)207915 1127; Tel: +44 (0)20 79151041 ${ }^{b}$ Institute of Medical and Biological Engineering, School of Mechanical Engineering, University of Leeds, Leeds, LS2 9JT, UK

${ }^{c}$ Materials Chemistry Research Centre, Department of Chemistry, University College London, 20 Gordon Street, London, WC1H OAJ, UK
}

biofilm modes of growth which persist in catheters and preventing biofilm accumulation.

Methylene Blue (MB) is a photosensitiser i.e. it is capable of producing highly reactive species such as oxygen radicals when exposed to an electromagnetic wave of the appropriate wavelength. The resulting Reactive Oxygen Species (ROS) can kill microbes and the process is termed lethal photosensitisation. Lethal photosensitisation has been used to kill microorganisms in biofilms and those deposited on a surface ${ }^{3,4}$ but this is the first report suggesting their use for preventing the formation of biofilms. More recently, we have successfully developed polymers (silicone and polyurethane) with embedded photosensitisers such as $\mathrm{MB}^{5-8}$ or covalently bound to the surface. ${ }^{9}$ The antimicrobial properties of these materials may also be affected by the presence of gold nanoparticles. Nanoparticles of $2 \mathrm{~nm}$ in diameter have been shown to enhance the killing of Escherichia coli and Staphylococcus epidermidis when encapsulated in silicone with MB. ${ }^{8}$

To date, the antimicrobial properties of such materials have been demonstrated only against planktonic organisms $\mathrm{s}^{5-9}$ but not against adherent cells during biofilm formation.

This work shows, for the first time, how silicone embedded with MB and gold nanoparticles can reduce the extent of S. epidermidis biofilm formation when periodically exposed to laser light. The same amount of energy was used employing various combinations of irradiation time and frequency of exposure in order to establish the optimum process parameters. Furthermore, the effect of irradiation on the material properties, such as surface roughness and elasticity, was also investigated. 


\section{Results and discussion}

The overnight culture used for the flow-cell experiments was in stationary state and predominantly made of live cells as assessed by live-dead staining (data not shown).

$S$. epidermidis colonized the surface of untreated silicone immediately after the initial contact, the proportion of area covered by the biofilm increased rapidly and reached about $80 \%$ after about 3 hours. In the flow cell experiment, the area covered by bacterial cells carried on increasing and the surface was completely covered after 5 hours (Fig. 1-3). An image of S. epidermidis biofilm after this time is presented in Fig. 4c.

The adhesion of S. epidermidis to silicone containing MB and $\mathrm{Au}$ nanoparticles followed the same pattern until the first laser irradiation in any of the exposure length/frequency combinations used in this study (Fig. 1-3).

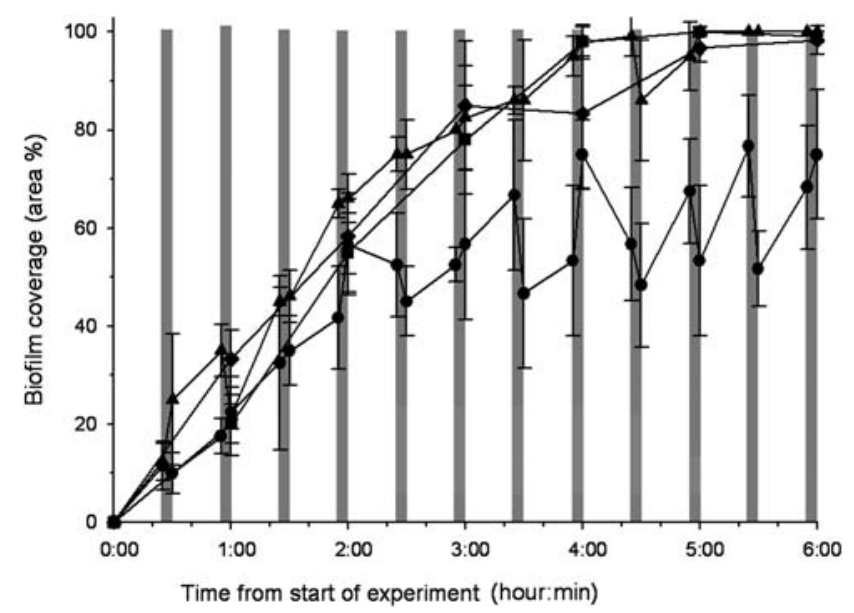

Fig. $1 S$. epidermidis biofilm formation during periodic laser light exposure of $5 \mathrm{~min}$ every $30 \mathrm{~min}(\mathrm{~L}=$ laser and $\mathrm{S}=$ sensitiser $)$. Grey areas denote time periods during which the material was exposed to laser light.

- $\mathrm{L}+\mathrm{S}+, \boldsymbol{\Delta}, \mathrm{L}+\mathrm{S}-, \mathbf{\square}, \mathrm{L}-\mathrm{S}-$, and $\bullet \mathrm{L}-\mathrm{S}+$.

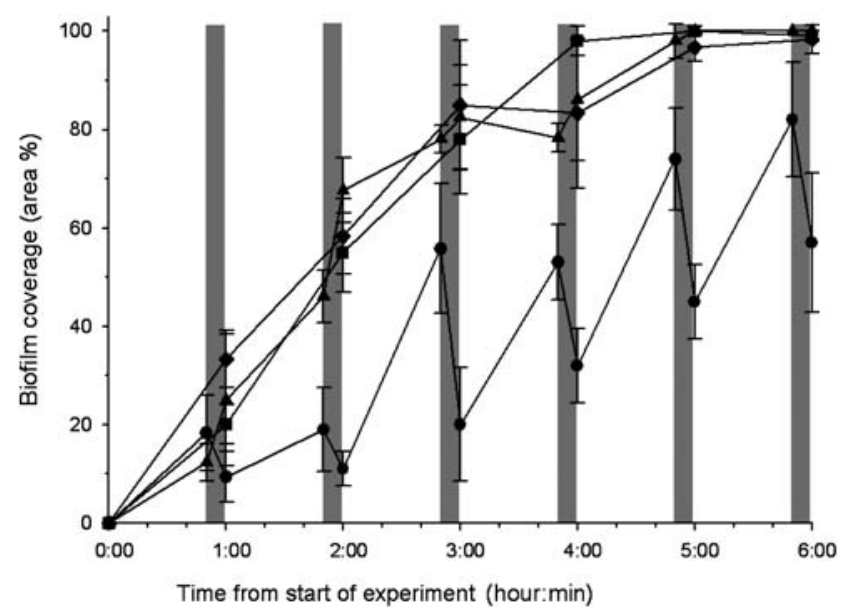

Fig. 2 S. epidermidis biofilm formation during periodic laser exposure 10 min every $60 \min (\mathrm{L}=$ laser and $\mathrm{S}=$ sensitiser $)$. Grey areas denote time periods during which the material was exposed to laser light. $-\mathrm{L}+\mathrm{S}+$, $\Delta \mathrm{L}+\mathrm{S}-, \mathbf{\square} \mathrm{L}-\mathrm{S}-$, and $\bullet \mathrm{L}-\mathrm{S}+$.

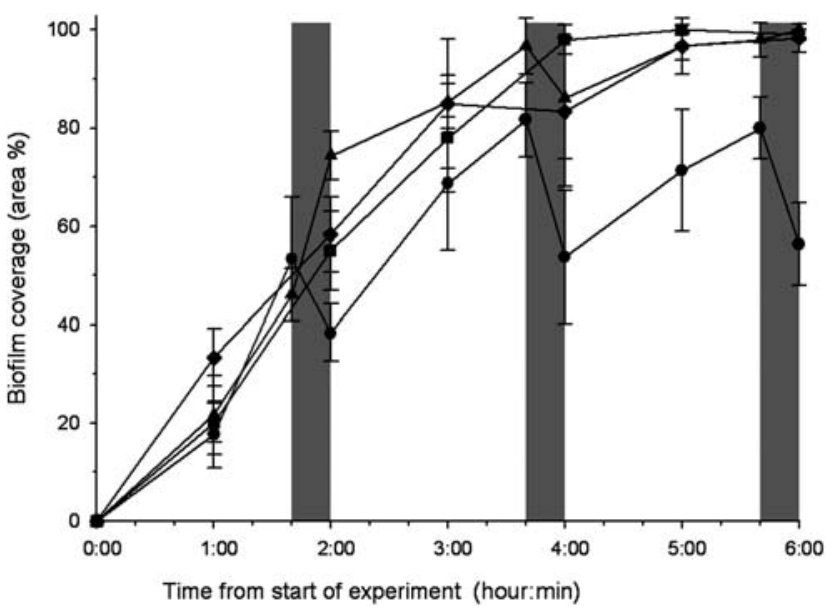

Fig. 3 S. epidermidis biofilm formation during periodic laser exposure 20 min every $120 \mathrm{~min}(\mathrm{~L}=$ laser and $\mathrm{S}=$ sensitiser). Grey areas denote time periods during which the material was exposed to laser light. $\bullet \mathrm{L}+$ $\mathrm{S}+, \boldsymbol{\Delta} \mathrm{L}+\mathrm{S}-, \mathbf{\square} \mathrm{L}-\mathrm{S}-$ and $\bullet \mathrm{L}-\mathrm{S}+$.

After each period of irradiation, the biofilm present on the surface increased again until the next exposure to laser light, this behavior generated a seesaw like profile of the proportion of surface colonized by S. epidermidis (Fig. 1-3). Examples of S. epidermidis biofilm before and after laser irradiation are in Fig. $4 \mathrm{a}$ and $\mathrm{b}$. The amount of biofilm accumulating on surfaces exposed to laser light was never as great as that on untreated silicone in any of the exposure length/frequency combinations used in this study (Fig. 1-3). The adhering cells, assessed by live-dead staining, were almost completely alive both before and after laser exposure or on the control materials (data not shown).

The proportion of the surface colonized by S. epidermidis after six hours was $75 \%$ when the laser light exposure was $5 \mathrm{~min}$ and applied every $30 \mathrm{~min}$ (Fig. 1); it was $47 \%$ when the laser light exposure was $10 \mathrm{~min}$ and applied every $60 \mathrm{~min}$ (Fig. 2) and finally was $56 \%$ when the laser light exposure was $20 \mathrm{~min}$ and applied every $120 \mathrm{~min}$ (Fig. 3).

In all cases, the biofilm formation pattern on the material containing MB but not exposed to laser light $(\mathrm{L}-\mathrm{S}+)$ and the original silicone without $\mathrm{MB}$ exposed to laser light $(\mathrm{L}+\mathrm{S}-)$ was the same as the profile obtained on untreated material not irradiated $(\mathrm{L}-\mathrm{S}-)$.

The material properties (surface roughness and elasticity) of silicone containing MB and gold nanoparticles reported in Table 1 show that the surface roughness of the sample decreased progressively during laser irradiation $(p<0.05)$, whilst the elasticity of the material and the relative elongation at breaking point were not affected by the laser exposure $(p<0.05)$.

The asperity density (Table 2 ) decreased with energy dose, the number of asperity decreased to about a fifth of the initial value after the highest laser light exposure tested. The average height of an asperity did not change remarkably during the laser light exposure; however, the standard deviation increased significantly. The asperity height frequency distribution (Fig. 5) showed an initial increase of the asperities whose height was close to the reference plane whilst a longer treatment resulted in a more spread distribution. 
(a)

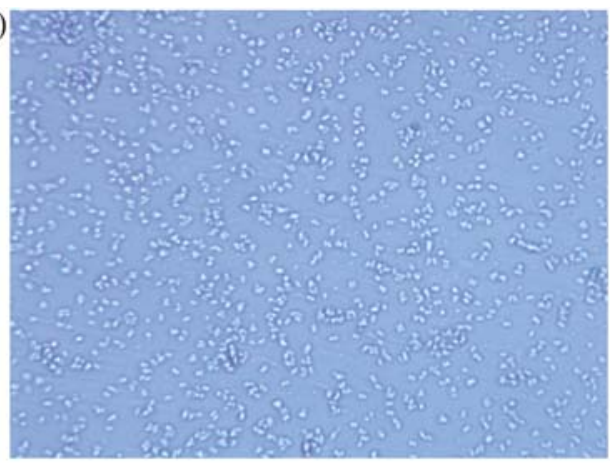

(b)

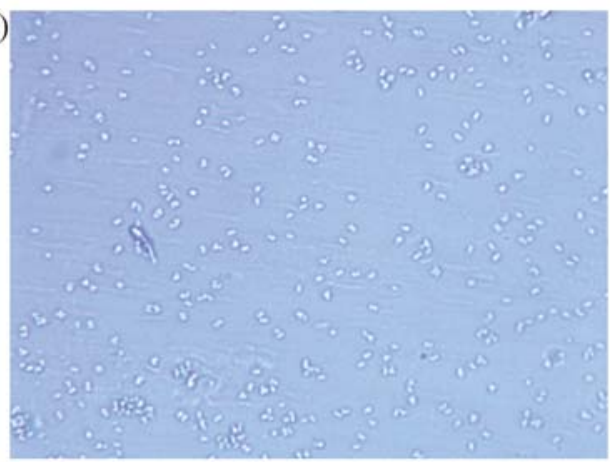

(c)

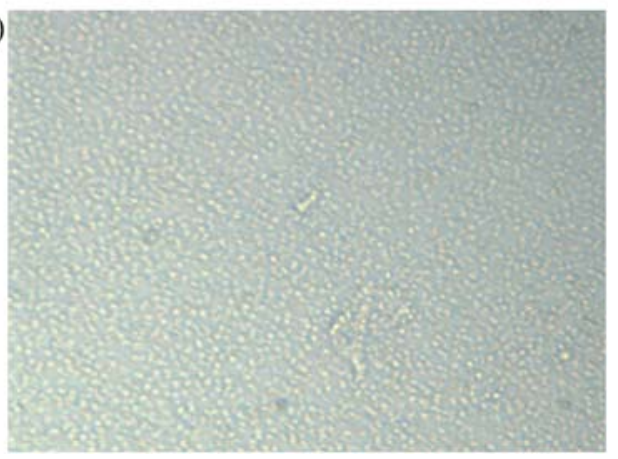

Fig. 4 Microscopy images of S. epidermidis biofilm before laser light exposure (a), after exposure to laser light (b) and on silicone after 6 hour resulting in $100 \%$ coverage (c).

The mechanism of microbial inactivation during lethal photosensitisation is assumed to be through the production of ROS when the photosensitiser is exposed to light of an appropriate wavelength. ${ }^{10}$ Light-activated materials containing various photosensitisers have been prepared and the antimicrobial properties of the photosensitisers are retained when embedded in a polymeric matrix such as silicone or polyurethane. ${ }^{5-8}$ Furthermore,

Table 1 Surface roughness and elasticity module of silicone containing $\mathrm{MB}$ and $\mathrm{Au}$ nanoparticles after different levels of irradiation

\begin{tabular}{lllll}
\hline $\begin{array}{l}\text { Energy } \\
\text { deposited } / \mathrm{J} \mathrm{cm}^{-2}\end{array}$ & $R_{\mathrm{a}} / \mathrm{nm}$ & $R_{\mathrm{q}} / \mathrm{nm}$ & $\begin{array}{l}\varepsilon \text { at } \\
\text { breaking } \\
\text { point }\end{array}$ & $\begin{array}{l}\text { Young's } \\
\text { module/MPa }\end{array}$ \\
\hline 0 & $21.5 \pm 2.1$ & $80.5 \pm 7.1$ & $>5$ & $1.05 \pm 0.02$ \\
58.5 & $19.0 \pm 2.0$ & $46.4 \pm 6.3$ & $>5$ & $1.15 \pm 0.08$ \\
117.0 & $18.5 \pm 2.2$ & $26.9 \pm 4.9$ & $>5$ & $1.03 \pm 0.03$ \\
\hline
\end{tabular}

Table 2 Asperity density and asperity height distribution parameter after laser irradiation

\begin{tabular}{lrrl}
\hline Energy deposited $/ \mathrm{J} \mathrm{cm}^{-2}$ & $\mu / \mathrm{nm}$ & $\sigma / \mathrm{nm}$ & Density/asp m \\
\hline 0 & 2.81 & 19.54 & $3.94 \times 10^{12}$ \\
58.5 & -3.76 & 17.26 & $3.47 \times 10^{12}$ \\
117.0 & 2.21 & 31.64 & $8.15 \times 10^{11}$ \\
\hline
\end{tabular}

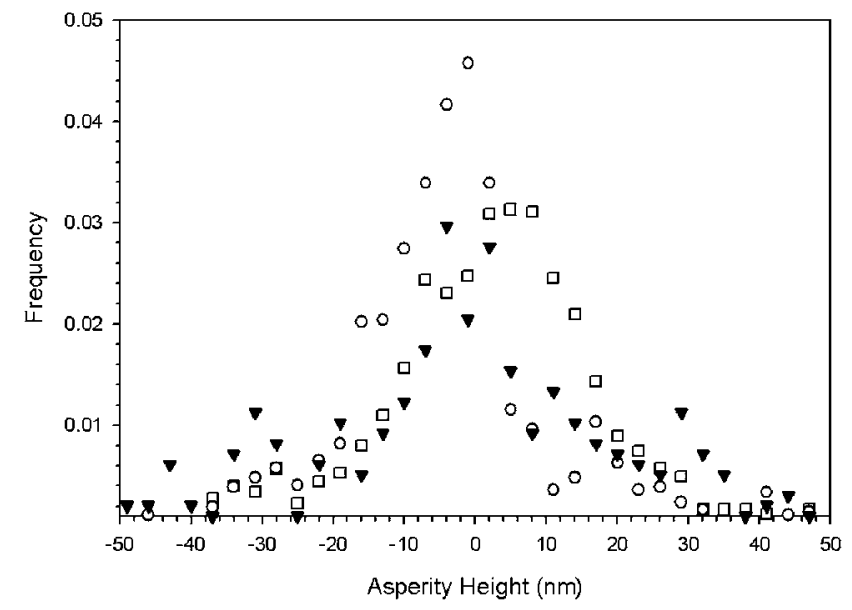

Fig. 5 Frequency distribution of asperity height after different energy doses: $\square 0 \mathrm{~J} \mathrm{~cm}^{-2}, \bigcirc 58.5 \mathrm{~J} \mathrm{~cm}^{-2}$ and $\boldsymbol{\nabla} 117.0 \mathrm{~J} \mathrm{~cm}^{-2}$.

gold nanoparticles of $2 \mathrm{~nm}$ diameter are also capable of enhancing the antimicrobial properties of silicone containing MB. ${ }^{5,8}$ However, these studies demonstrated antibacterial activity only against planktonic cells and these are known to be generally more susceptible to antimicrobial agents. ${ }^{11}$ This work has demonstrated for the first time that these materials are also effective at inhibiting biofilm formation and can reduce the extent of surface colonization. One of the appealing features of lethal photosensitisation is that the mode of action (through ROS) is unlikely to result in the selection of a resistant population $^{12}$ as in the case of antibiotics.

It is known that laser irradiation can result in the inactivation of the photosensitiser (photobleaching), therefore continuous irradiation was not employed during the study in order to preserve the activity of the photosensitiser for longer periods of time. In all of the experiments, the overall energy dose was the same and different combinations of irradiation time and frequency of exposure were made in order to determine the optimum conditions.

When the photosensitiser is embedded in the silicone matrix the ROS are produced at the interface between the silicone substrate and the liquid, this mechanism generates lethal compounds exactly where they are needed to disrupt adherent cells. It is also interesting to note that the ROS appear to affect the microbial cells in a way that causes their detachment from the surface. It is possible that the external bacterial structures responsible for the adhesion to the surface, such as pili and adhesion proteins are the first to be affected by the ROS. If these structures are damaged by ROS, it is postulated that this may cause the cell to detach. It is possible that the cells are first killed and once dead they detach from the surface, however, this latter 
mechanism is less likely as many studies have reported the presence of dead cells attached to surfaces. ${ }^{13}$ The results show that longer irradiation periods $(20 \mathrm{~min})$ result in higher biofilm removal after each treatment; however, the longer interval between the exposures allowed the biofilm to significantly re-grow (Fig. 3). Conversely, very frequent irradiation (every 30 min) but of short duration $(5 \mathrm{~min})$ resulted in a minimal regrowth of the biofilm between exposures (Fig. 1), however, under these conditions, the removal achieved after each irradiation was minimal because of the short duration.

The combination of $10 \mathrm{~min}$ exposure every hour (Fig. 2) resulted in the best overall performance.

Furthermore, the experiments performed both on the material not containing $\mathrm{MB}$ but exposed to laser light $(\mathrm{L}+\mathrm{S}-)$ and the material containing $\mathrm{MB}$ but not irradiated $(\mathrm{L}-\mathrm{S}+$ ) confirmed that, neither the photosensitiser alone, nor the laser light itself was responsible for the reduced biofilm formation but it is the combination of the MB and the laser light that results in antibiofilm activity.

There are some studies suggesting that MB might have dark toxicity on bacterial cultures, ${ }^{\mathbf{1 4}, 15}$ however, this is seen at MB concentration of the order of $\mu \mathrm{M}$, whilst the concentration of $\mathrm{MB}$ in the silicone sample used here ${ }^{5}$ is about $1 \mathrm{nM} \mathrm{mm} \mathrm{mm}^{-3}$ explaining the absence of dark toxicity seen in Fig. 1-3. Furthermore, previous works have demonstrate that Au nanoparticles alone do not show toxicity towards bacteria ${ }^{5,6,8}$ whilst both silicone and polyurethane containing only MB exhibit lower antimicrobial properties that the same material containing also 2 nm Au nanoparticles. ${ }^{5,6}$

There have been a number of recent reports regarding the antibiofilm potential of lethal photosensitisation. ${ }^{4,16}$ However, the approach used in these studies involved depositing a solution of photosensitiser onto the biofilm followed by irradiation, in comparison to the present work where the photosensitiser was embedded in a polymeric matrix and the antimicrobial ROS are produced at the solid/liquid interface rather than inside the bacterial cells. This different approach could explain why, in those studies, the biofilm after irradiation appeared to be composed of dead cells still attached to the surface, whilst in our study the biofilm cells detached from the surface after irradiation. Our approach appears to be more suitable for preventing bacterial colonization of catheters, as it would not require flushing the catheter with a solution of photosensitiser, the latter being already embedded in the material. Furthermore, the cell concentration used in this work is higher than in urine because of its lower nutrients concentration, therefore, it is likely that lethal photosensitisation would work better in catheters because of the smaller number of microorganism attached on the surface.

The effect of laser irradiation on the material properties was investigated with regard to both the surface roughness and elasticity, as potentially the radical oxygen species are able to interact not only with the bacteria deposited or near the surface, but also with the polymeric material. Exposure to radical species produced during gas plasma sterilization has been shown to result in weakening of polyurethane; ${ }^{17,18}$ a reduction of the elasticity or the material becoming more brittle are undesired effect as they would cause problems during catheter removal, consequently making light-activated materials less suited for catheter production. The results shown here demonstrated that exposure to laser light did not modify the elasticity or breaking point of silicone containing MB. The experimental set-up did not permit a relative deformation greater than five times the initial length; however, even if laser light exposure resulted in the material been more brittle, the silicone could still be stretched to a length five times its initial dimension; this situation is highly unlikely to occur during normal catheter insertion/removal. However, the irradiation appeared to reduce the surface roughness, the data show both a reduction in the number of asperities and their height. A possible explanation is that the material located in the asperities is eroded during the treatment and therefore the asperities are 'consumed'. It is interesting to note that irradiation did not affect each asperity in the same way as noticeable from the change in the standard deviation of the asperity height distribution. The highest asperity were affected more than the lowest ones as demonstrated by the initial increase in the frequency of lower asperities. Smoother surfaces are less favorable towards bacterial colonization $^{19}$ and, therefore, the effect of laser irradiation on the surface roughness can act synergistically with the production of ROS in reducing biofilm accumulation.

\section{Experimental}

\section{Polymer preparation}

Medical grade silicone elastomers were prepared using liquid MED-4850 (Polymer Systems Technology Ltd.) as a starting material; this was mixed with the crosslinking agent in a $1: 1$ ratio and spread uniformly onto a glass surface to make a $1.9 \mathrm{~mm}$ thick sheet. The polymer was cured at $80{ }^{\circ} \mathrm{C}$ for 3.0 hours and then allowed to cool.

Methylene Blue (MB, Sigma, UK) solutions were prepared at a concentration of $700 \mathrm{ppm}$ in acetone : aqueous solution. Aunanoparticles were added in the ratio of $9: 1$ acetone : aqueous solution. The solutions were sonicated in an ultrasound bath for 15 minutes to ensure complete $\mathrm{MB}$ dissolution., ${ }^{5,6,8} \mathrm{Au}$ nanoparticles were purchased from BBInternational Ltd. (Cardiff, UK) and were stated to be $2 \mathrm{~nm}$ in diameter and at a concentration of $1.5 \times 10^{14}$ particles per $\mathrm{ml}$.

A silicone piece was cut from the sheet prepared as described above with the following dimension: $25 \times 6 \times 1.9 \mathrm{~mm}$; this is the size of the space in the flow cell device that contains the tested material.

Each silicone piece was placed into an MB solution and left to swell in the dark for 24 hours inside a closed bottle containing $20.0 \mathrm{ml}$ of the solution. After this time the samples were left to dry in the dark at room temperature for 24 hours. The resulting silicone contained $\mathrm{MB}$ and $\mathrm{Au}$ nanoparticles homogeneously distributed in the matrix. ${ }^{5,6,8}$ Untreated pieces of silicone (not swollen in any solvent) were used as blanks.

\section{Microbial cultures}

S. epidermidis RP62a was maintained by weekly subculture on Brain Heart Infusion (BHI) Agar (Oxoid, Basingstoke, UK). For experimental purposes, the bacteria were grown aerobically in 15 $\mathrm{ml}$ of BHI broth (Oxoid) statically at $37{ }^{\circ} \mathrm{C}$ overnight, then $5 \mathrm{ml}$ of this cell suspension were aseptically added to $495 \mathrm{ml}$ of sterile PBS (resulting in a cell concentration of about $10^{7} \mathrm{CFU} \mathrm{ml}{ }^{-1}$ ) and kept under mild agitation by a magnetic stirrer. 


\section{Flow-cell apparatus}

Biofilms were grown in an apparatus that consisted of a 11 flask containing $495 \mathrm{ml}$ of sterile PBS and connected to a flow-cell (FC 71, BioSurface Technologies Corporation, Bozeman, MT, USA); a bubble trap device was inserted just before the flow cell (Fig. 6). This flow-cell model is designed to allow the study of biofilms on different materials; this is achieved through the insertion of a piece of the material of interest in an appropriate space $(25 \times 6$ $\times 1.9 \mathrm{~mm})$.

The cell suspension (described earlier) was pumped from the flask to the flow-cell via a peristaltic pump (Model $101 \mathrm{U} / \mathrm{R}$, Watson-Marlow Ltd., Falmouth, UK) and back to the flask; the

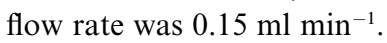

The bacterial suspensions were maintained in an incubator at $37^{\circ} \mathrm{C}$. However, the flow-cell and bubble trap were mounted on a microscope stage and were therefore maintained at room temperature.

Flow-cells containing silicone with embedded MB were irradiated with light $(660 \mathrm{~nm})$ from a $230 \mathrm{~mW}$ laser (Periowave, Ondine Biopharma Inc., Vancouver, Canada). The irradiation power density employed was $0.0325 \mathrm{~W} \mathrm{~cm}^{-2}$. The total energy dose during a 6 hour long experiment was $117.0 \mathrm{~J} \mathrm{~cm}^{-2}$ and it was delivered in steps of varying periods of time and at different intervals; for $5 \mathrm{~min}$ every $30 \mathrm{~min}, 10 \mathrm{~min}$ every $60 \mathrm{~min}$ or $20 \mathrm{~min}$ every $120 \mathrm{~min}$.

The surface of the silicone piece inserted in the flow-cell was examined with a microscope (BX51, Olympus, Hertfordshire, UK) attached to a digital camera (MicroPublisher Digital Camera 5.0 RTV, QImaging, UK). At prefixed times, images were taken in 5 random positions on the sample surface and stored on a hard disk using SimplePCI ver. 6.2, Compix Inc., PA, USA.

\section{Image analysis}

The analysis of the images was later performed with ImageJ software (National Institutes of Health, USA http://rsbweb.nih.gov/ij/). The area covered by the biofilm ( $\left.A_{\text {biofilm }}\right)$ was selected and measured with software function. At the same time the area of the entire image $\left(A_{\text {tot }}\right)$ was calculated and the percentage of area covered by the film calculated as follow:
When no cells are adhering the result is $0 \%$, whilst when no surface is left uncolonised the result is $100 \%$.

\section{Statistical analyses}

The Mann-Whitney $U$ test was used to compare the fraction of surface covered by biofilm from the various elastomer samples $(\mathrm{L}+\mathrm{S}+, \mathrm{L}+\mathrm{S}-$, and $\mathrm{L}-\mathrm{S}+)$ with the control samples $(\mathrm{L}-\mathrm{S}-)$. For all analyses, $p<0.05$ was considered statistically significant.

\section{Material properties}

The mechanical properties of the samples were studied by performing standard stress-strain analysis (ASTM D882-02) with a Texture Analyser TA.XT plus (Stable Micro Systems Ltd., UK) using tensile grips (A/TG) and a load cell equal to $30 \mathrm{~kg}$. Samples $1.0 \mathrm{~mm}$ thick and $6.0 \mathrm{~mm}$ wide were stretched at a speed of $8.0 \mathrm{~mm} \mathrm{~min} \mathrm{~m}^{-1}$ and with the initial distance between the grips of $50 \mathrm{~mm}$; the load applied was measured up to the breaking of the sample and the Young's modulus along with the fracture load was calculated.

The topography and surface roughness of each sample were examined using atomic force microscopy (AFM, Nanoscope IV, Digital Instruments) in tapping mode. For all the sample types, the scan was performed on an area size of $20 \times 20 \mu \mathrm{m}$, at scan velocity of $40 \mu \mathrm{m} \mathrm{s}^{-1}$ and at scan frequency equal to $1.0 \mathrm{~Hz}$. The average surface roughness value $R_{\mathrm{a}}$ and the root mean square surface roughness value $R_{\mathrm{q}}$ were assessed at each scan and the average values of at least five independent scans are reported.

The surface coordinates were obtained from the AFM scans and analyses to determine the location and height of each asperity. This was done on an in-house FORTRAN code imposing the condition that an asperity is present if the neighbouring points on the surface have lower height. This is mathematically expressed as: ${ }^{20}$

$$
\begin{gathered}
z(i, j) \in \text { asperities } \Leftrightarrow z(i, j)>z(m, n) \text { with } m=i-1, i, i+1 ; \\
n=j-1, j, j+1 \text { and } m, n \neq i, j
\end{gathered}
$$

Once the asperities were located, their height was calculated against a reference plane equal to average of all coordinates and the distribution determined.

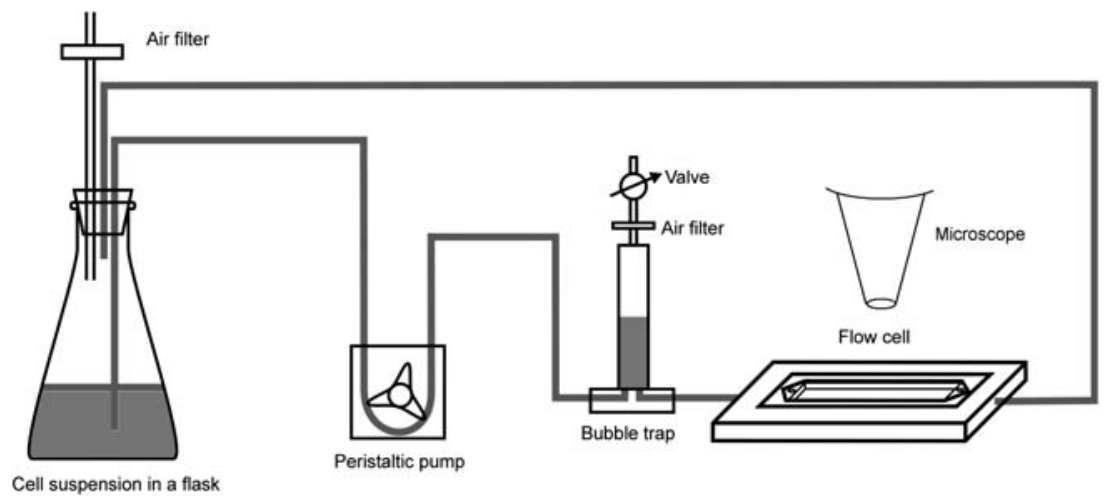

Fig. 6 Schematic lay out of the biofilm test apparatus. 


\section{Conclusions}

Our results have demonstrated for the first time that lethal photosensitisation can be applied to prevent the accumulation of biofilms on surfaces of silicone. Furthermore, the effect depends on the combination of irradiation time and frequency of laser light exposure; longer irradiation times were more effective at preventing biofilm accumulation but less frequent light exposure allowed greater biofilm re-growth. The elasticity of the materials did not change during the laser light exposure whilst the surface roughness decreased with irradiation.

A catheter made of light-activated materials with laser light periodically irradiated through an optical fiber placed in the lumen is envisaged as a device capable of reducing catheter acquired infections.

\section{Acknowledgements}

JP, MW and IPP thank the BBSRC for supporting this work through grant BB/E012310/1. IPP thanks the Royal Society/ Wolfson Trust for a merit award.

\section{References}

1 Department of Health, The Health Act 2006: Code of Practice for the Prevention and Control of Healthcare Associated Infections, Department of Health, 2008, pp. 1-39.

2 S. Noimark, C. W. Dunnill, M. Wilson and I. P. Parkin, Chem. Soc. Rev., 2009, 38, 3435-3448.

3 M. S. Sbarra, A. Di Poto, C. R. Arciola, E. Saino, M. Sharma and F. Bragheri, et al., Int. J. Artif. Organs, 2008, 31(9), 848-857.
4 M. Sharma, L. Visai, F. Bragheri, I. Cristiani, P. K. Gupta and P. Speziale, Antimicrobial Agents and Chemotherapy, 2008, 52(1), 299-305.

5 S. Perni, C. Piccirillo, J. R. Pratten, P. Prokopovich, W. Chrzanowski and I. P. Parkin, et al., Biomaterials, 2009, 30(1), 89-93.

6 S. Perni, P. Prokopovich, C. Piccirillo, J. R. Pratten, I. P. Parkin and M. Wilson, J. Mater. Chem., 2009, 19(18), 2715-2723.

7 S. Perni, C. Piccirillo, P. Prokopovich, J. R. Pratten, I. P. Parkin, M. Wilson, J. Biomed. Appl., DOI: 10.1177/0885328209352701.

8 S. Perni, C. Piccirillo, A. Kafizas, M. Uppal, J. R. Pratten, M. Wilson et al. J. Cluster Sci., DOI: 10.1007/s10876-010-0319-5.

9 C. Piccirillo, S. Perni, J. Gil-Thomas, P. Prokopovich, M. Wilson and J. Pratten, et al., J. Mater. Chem., 2009, 19(34), 6167-6171.

$10 \mathrm{C}$. Yu, T. Canteenwala, L. Y. Chiang, B. Wilson and K. Pritzker, Synth. Met., 2005, 153, 37-40.

11 K. Smith, A. Perez, G. Ramage, C. G. Gemmell and S. Lang, Int. J. Antimicrob. Agents, 2009, 33(4), 374-378.

12 M. R. Hamblin and T. Hasan, Photochem. Photobiol. Sci., 2004, 3, 436-450.

13 R. Lisbeth, P. Moller and T. Tolker-Nielsen, Appl. Environ. Microbiol., 2009, 75(6), 1674-1678.

14 M. Wainwright, D. A. Phoenix, S. L. Laycock, D. R. Wareing and P. A. Wright, FEMS Microbiol. Lett., 1998, 160, 177-181.

15 M. Wainwright, D. A. Phoenix, J. Marland, D. R. Wareing and F. J. Bolton, FEMS Immunol. Med. Microbiol., 1997, 19, 75-80.

16 A. Di Poto, M. S. Sbarra, G. Provenza, L. Visai and P. Speziale, Biomaterials, 2009, 30(18), 3158-3166.

17 A. Simmons, J. Hyvarinen and L. Poole-Warren, Biomaterials, 2006, 27, 4484-4497.

18 S. Lerouge, C. Guignot, M. Tabrizian, D. Ferrier, N. Yagoubi and L. Yahia, J. Biomed. Mater. Res., 2000, 52(4), 774-782.

19 A. Almaguer-Flores, L. A. Ximenez-Fyvie and S. E. Rodil, J. Biomed. Mater. Res., Part B, 2010, 92(1), 196-204.

20 P. Prokopovich and S. Perni, ACTA Biomaterialia, DOI: 10.1016/ j.actbio.2010.05.007. 